\title{
Supporting Online Collaborative Design for Teacher Professional Development
}

This paper describes a study on online collaborative design in the context of teacher professional development. 25 teachers from different Spanish universities and disciplines participated in the study. The aim was to understand how to support teachers in interuniversity teams to collaborate fully online along the learning design process of a discipline-based situation that integrates ICT, a problem scarcely tackled in the literature. The described interpretive study, using mixed methods, explores the support to online co-design provided by a novel ICT community platform named ILDE (Integrated Learning Design Environment). Lessons drawn from the results can contribute to the improvement of online collaborative design processes in the context of teacher professional development.

Keywords: collaborative design; learning design; teacher professional development, online learning.

\section{Introduction}

Conole (2013, p.7) defines Learning Design (LD) as the "methodology that allows teachers/designers to take informed decisions on their design of learning activities and interventions, making an effective use of resources and technologies, moving from the conceptualization of their design ideas to their implementation using a range of tools and resources". LD fosters the role of "Teachers as Designers" (Laurillard, 2012; McKenney, Kali, Markauskaite, \& Voogt, 2015; Shamir-Inbal \& Kali, 2009): teachers need to systematize, make explicit and share their decisions of pedagogical designs (in artefacts called "learning designs"), so as to promote reflection on their professional performance, to incorporate good practices and, ultimately, to improve the quality of their teaching, while creating a sense of community.

In addition to the ultimate goal of promoting "Teaching as Design", research on LD has also focused on supporting teachers when integrating ICT with active pedagogies. Indeed, LD can illustrate "how teachers sequence student learning experiences, and, most importantly, how the various TPACK domains are balanced against each other" (Dobozy \& Campbell, 2014, p.104). TPACK (Technological Pedagogical Content Knowledge: Mishra \& Koehler, 2006) refers to the knowledge that teachers must possess to design learning activities, including technological, pedagogical and subject matter content issues. Therefore, TPACK and LD are seen as complementary concepts and their synergy could help teachers understand how theory can be enacted in their educational practice. Consequently, several research studies have explored different approaches to the use of LD for Teacher Professional Development (TPD) aimed at fostering ICT integration (Conole \& Culver, 2009; Author, 2014; Kali, Markauskaite, Goodyear \& Ward, 2011; Author, 2016; Mor \& Mogilevsky, 2013; Voogt et al., 2015). 
Regarding the improvement of teaching practice with ICT, LD has also recently been linked, in TPD contexts, to the importance of collaborative design of curricula (Ronen-Fuhrmann \& Kali, 2015). Co-design offers opportunities for creativity, co-learning, motivation, engagement, and development of teachers' communities of practice (Laurillard, 2012); also, co-design leads to a model of co-created and co-facilitated learning (Reilly \& Literat, 2012). Additionally, sharing practices within LD may enhance the reuse of learning scenarios, which is especially relevant if they can be shared through virtual spaces (Gros, Escofet \& MarimónMartí, 2016). There are good examples of TPD communities in the LD field that are directed towards that aim (Conole \& Culver, 2009; Author, 2016; Mor \& Mogilevsky, 2013).

These research lines are complemented with the development of visual technological tools for $\mathrm{LD}$, aimed at supporting teachers in their design processes, making easier the integration of ICT in their practice. LD processes involve a wide range of design tasks that typically go from the ideation of the learning situations (also known as "conceptualization") to their actual enactment using ICT tools (tasks typically referred to as "implementation") (Author, 2016). Prieto et al. (2013) provide examples of LD tools supporting teachers along some or all of the phases of a LD process.

However, the previous studies have only explored the processes of co-design in specific phases of the LD lifecycle in the context of TPD, namely the conceptualization. That is why in this study we explore the processes of interaction for consensus and support for team design in online environments through the whole lifecycle of LD, aimed at TPD for ICT integration. The study involves an online course for university teachers, who participated in a co-design project, grouped according to their field of knowledge. The teachers used the Integrated Learning Design Environment (ILDE) (Author, 2014), a community environment for teachers where they can use different technological tools to (co-)create learning designs.

The posed research question was "how to support teachers in interuniversity teams to collaborate fully online along the LD process of a discipline-based situation that integrates ICT?". Therefore, we analyse how the ILDE online co-design support helps educators reach consensus and follow a full-lifecycle design process with ICT. This study has implications both for: the whole community of teachers, regarding TPD and the support of effective technology integration in teaching practice; and, LD tools developers, who can consider the possibilities and limitations for co-design in ILDE and develop/adapt tools that enhance codesign.

\section{Collaborative Design in TPD}

One increasingly fostered form of TPD proposes teacher involvement in collaborative design of curricula (Ronen-Fuhrmann \& Kali, 2015; Voogt et al., 2015). Gros, Escofet and Marimón-Martí (2016) state that LD is a relevant way to guide teacher practice because it connects problems with learning solutions, creates a reusable knowledge base, encourages 
reflection on the learning processes, and enhances knowledge transfer and learning of good practices.

Some meaningful experiences in learning co-design for TPD can be pointed out.

- Voogt et al. (2015) identify three key features of learning in collaborative design processes: situatedness (authentic and meaningful contexts), agency and sense of ownership, and the cyclical nature of learning and change.

- Kali, Markauskaite, Goodyear and Ward (2011) identify four unique characteristics that make co-design processes productive: multi-dimensional exploration, balanced process, mutual respect and cross-domain expertise.

- Gros, Escofet and Marimón-Martí (2016) combine learning co-design with an inquiry-based approach for TPD as a way of eliciting LD patterns.

All of these studies focus on the conceptualization phase and there is no evidence of the actual authoring and implementation of their learning scenarios, which would mean the necessary direct connection to the teaching practice and ICT integration.

\section{Supporting the full learning co-design lifecycle}

There exists a full range of technological tools to support teachers in LD. However, most of them are lack flexibility, they focus only on specific parts of the LD process (e.g. conceptualization or authoring) and they lack community features.

The ILDE (http://ilde.upf.edu/about; Author, 2014) overcomes LD tooling shortcomings by providing a set of integrated tools for the creation of learning designs (LD solutions: LdS). In ILDE, teachers can work individually or collaboratively with other teachers thanks to a set of provided community features. The ILDE is built on top of the LdShake social platform (Author, 2011) and provides different tools for teachers along the complete LD lifecycle (conceptualization, authoring and implementation), which is described by Author (2016, p. 174) as follows: first, the conceptualization phase refers to the ideation of the learning situations including objectives, structure of contents, and possible activities to be proposed (macro-design); second, the authoring phase includes the systematization and contextualization of the macro-design by detailing the activity flow and defining each activity (instructions, tools, learning resources, etc.); and, third, the implementation phase deals with the automatic setting up of the technological platform for enacting the design, typically involving a Learning Management System (LMS).

The ILDE's community features include (Author, 2014): team formation, storage and retrieval of shared designs, and co-design support (e.g., design versioning and commenting, co-edition, etc.)

Although the ILDE has previously been used in TPD (Author, 2011; Author, 2014), the existing studies have been limited to a specific part of the learning (co-)design lifecycle (the 
conceptualization) in mostly face-to-face contexts. However, in the current TPD study, we explore the possibility to support the complete learning (co-)design lifecycle fully online, with a special focus on ILDE's co-design support.

\section{The study}

The research question explored in this study, which was derived from the identified gap in the literature concerning whole lifecycle learning co-design, was: How to support teachers in interuniversity teams to collaborate fully online along the LD process of a discipline-based situation that integrates ICTs?

The study is interpretive in nature since it tries to understand the particularity and richness of the phenomena under study, in this case the ILDE support for online co-design in Higher Education. This particular situation is approached in conditions as authentic as possible, gathering mostly qualitative evidence, and not trying to obtain statistically-significant results or generalizations (Guba, 1981).

The main research question is contextualised within the presented study by defining the following issue that will guide the interpretation of the data: How does the ILDE online codesign support help educators reach consensus and follow a full-lifecycle design process?

\section{Context}

The study has been conducted in an online course within the Annual Programme of University Teacher Training of the nonprofit organization G-9 Universities (https://www.unig9.net/).

The course, entitled "Design of Didactic Activities through the use of the ILDE", was organised by the University of the Balearic Islands (UIB) and carried out in April 2016. The estimated overall effort of the participants, including individual and/or collaborative online activities, was 15 hours. The learning environment managing resources and announcements of the course was Campus Extens, the institutional Moodle-based LMS of the UIB. However, the main tasks of the course were conducted through the ILDE and its integrated tools (Figure 1). The course coordinator acted as a facilitator, solving the teachers' doubts and problems, as well as providing them with feedback through the forums in Moodle and publishing comments in the ILDE.

Figure 1. Description of the TPD course explored in the study. WebCollage and Glue!-PS are authoring and implementation tools, respectively, integrated within the ILDE.

The findings from the literature on the topic of collaborative design in TPD were considered in the instructional model of the course. The participating teachers had to work in groups 
according to their teaching context (authentic and meaningful context), to change their designs according to the discussion on learning aspects and recommendations (cyclical nature of learning), subsequently modifying and sharing them (agency and sense of ownership) (Voogt et al., 2015). Although the groups were formed considering the disciplines of knowledge, each participant within the group had a specific domain of expertise, thus enriching and balancing the co-design process with cross-domain expertise (Kali, Markauskaite, Goodyear \& Ward, 2011).

25 out of the 33 initially enrolled teachers finished the course successfully. 22 teachers formed 9 teams according to their teaching field (see Table 1). The remaining 3 teachers worked individually due to inactivity/dropouts in their groups and, therefore, were not included in the study. Except for G12 and some of the members of G8, all group members were from different universities.

Table 1. Configuration of the groups in the course.

\section{Methodology}

The research design of the study follows an exploratory sequential mixed strategy. According to that strategy, data were first analysed with a quantitative approach and, after that analysis, some groups were selected as embedded units of analysis in single-cases (Yin, 2009). Thus, it was possible to analyse in more detail the results and explain them further using a qualitative approach. Moodle forums, comments on the designs, and open questions in the final questionnaire were treated qualitatively. On the other hand, activity logs, designs versions, and Likert scale questions in the final survey were processed quantitatively.

The analysis of the data gathered during the study was guided by a "data condensation" process (Miles, Huberman, \& Saldaña, 2013) (see Figure 2). The main issue of the study ("How does the ILDE online co-design support help educators reach consensus and follow a full-lifecycle design process?") is illuminated through two more specific topics:

- T1: Does the ILDE online co-design support help educators reach consensus about their design decisions? explores the way (and eventual difficulties) design teams are able (or not) to reach consensus about their designs.

- T2: Does the ILDE online support help educators complete a full-lifecycle codesign with ICT? explores whether the design teams were able to successfully complete their full-lifecycle co-design process using the ILDE, identifying emerging difficulties.

Figure 2. Data condensation diagram, inspired from Miles, Huberman and Saldaña (2013), showing the Research Question (RQ), Issue (I), topics (T), and informative questions (IQ). 
Table 2 summarises the data sources used in the study.

Table 2. Data sources and their definitions.

Figure 3 depicts the flow of data gathering and analysis techniques (labels are defined in Table 2) employed throughout the study. Data were analysed using the elements of the data condensation diagram of Figure 2 as the initial set of codes. Coding was carried out by three researchers, although the codes themselves were discussed and agreed by the whole research team, as suggested by Saldaña (2015). The closed items of the questionnaires and the activity logs from the ILDE were treated quantitatively, using descriptive statistics, so as to confirm (or not) the findings from the qualitative analysis. In order to contribute to the quality and credibility of the study, several steps were taken, including (Guba, 1981): triangulation of techniques and data sources; peer-debriefing between the three researchers that analised the data and the rest of the members of the research team (including the discussion and agreement of the data condensation schema); and, collection of thick descriptions of the context of the study.

Figure 3. Data gathering moments and analysis techniques during the study. See Table 2 for an explanation of the labels.

\section{Results}

\section{Topic T1: Does the ILDE online co-design support help educators reach consensus about their design decisions?}

In relation to how design teams reached consensus about their designs, as expected, we found different patterns of interaction among team members. According to the gathered evidence (Table 3 contains the selected excerpts of evidence for this section), the identified ways of collaboration were much more effective when based on the following aspects:

- Making explicit the changes that had been incorporated in the design and informing other members about it. After that, asking for feedback from group members. (see, e.g., $[\text { Posts }]^{1-\mathrm{A}},[\text { Posts }]^{4-\mathrm{A}}$ ).

- Distributing tasks and responsibilities among the group members (see, e.g., [Posts $]^{2-\mathrm{A}}$, [Posts $]^{10-A}$ ).

- Providing ideas about learning resources which could be included in the design (see, e.g., $\left.[\text { Posts }]^{5-\mathrm{A}}\right)$.

- Asking for and sharing clarifications about how to develop a particular procedure (see, e.g., $[\text { Posts }]^{2-\mathrm{B}}$, [Posts $]^{7-\mathrm{A}}$ ).

- Sharing opinions about the feedback provided by the course coordinator (see, e.g., $[\text { Posts }]^{2-\mathrm{C}}$, [ILDE-Post $]^{9}$ ).

- Giving solutions for coping with the required changes (see, e.g., [Posts $]^{7-B}$ ). 

(41 forum threads for a total of 230 messages approximately). However, at some point, several groups realized that the use of the commenting feature of ILDE was more suitable, since it allowed associating comments to each of the design artefacts the groups were creating (see, e.g., $[\text { Posts }]^{3-\mathrm{A}}$, [Posts $]^{4-\mathrm{B}}$ ). The participating teachers posted a total of 138 comments in the ILDE. Figure 4 shows how those comments were distributed among the 23 design artefacts that were edited by more than one teacher.

Figure 4. Distribution of ILDE comments among the 19 design artefacts that were edited by more than one teacher. The designs are identified by the group that created it, as well as by the tool used for its creation.

The encouraging above mentioned co-design interactions are reinforced by the opinions of several participants that reflect their positive attitude towards collaboration "because when you work in a collaborative team, you can achieve better designs" ([Quest-Post] ${ }^{2}$ ), although they also point out its challenging nature (see, e.g., [Quest-Post] ${ }^{7-A}$ ). Similarly, the organization of the course was also appraised by several groups, emphasizing the guidance provided by the facilitator (see, e.g., $[\text { GeneralForum }]^{2-\mathrm{A}},[\text { GeneralForum }]^{10-\mathrm{A}}$ ).

However, in not all cases the collaboration among group members was fruitful. For instance, in several cases the interactions within the groups had to do with communicating availability to contribute to the design rather than with making actual contributions, especially during the conceptualization phase (see, e.g., $[\text { Posts }]^{1-\mathrm{B}},[\text { Posts }]^{5-\mathrm{B}}$ ). It is true that sometimes they used the course forums to share their background and previous ideas about their teaching and learning experiences (see, e.g., $[\text { Posts }]^{8-\mathrm{A}}$ ). However, the actual decisions (and the associated rationale) that the group members made regarding their co-designs were not in many cases explicitly shared through the forums (see, e.g., $[\text { Posts }]^{3-B},[\text { Posts }]^{7-C}$ ). Thus, it was not uncommon that at some point in the interactions among the group members, one of them took the role of "editor" and made changes to the co-designs, without waiting for explicit decisions to be made (see, e.g., the interactions among group members in [Posts] ${ }^{8-\mathrm{B}}$ ).

In addition to the collaboration problems, the participating teachers identified additional difficulties. For instance, 7 (out of 9) design groups pointed out difficulties for finding time to devote to the course, as well as problems for synchronising those periods of availability among the group members, problems that might have impacted collaboration (see, e.g., $[\text { Posts }]^{1-\mathrm{D}}$, [GeneralForum $]^{2-\mathrm{B}}$, [Quest-Post $]^{3-\mathrm{A}},[\text { Posts }]^{5-\mathrm{B}},[\text { Quest-Post }]^{7-\mathrm{B}}$, [Posts $\left.]^{8-\mathrm{C}}\right)$. The participants also suggested improvements for the course regarding the collaboration and decision-making processes such as distributing tasks among the group members, assigning predefined roles, providing more time to deliver the tasks, etc. (see, e.g., [Quest-Post $]^{7-\mathrm{B}}$, $[\text { Quest-Post }]^{8}$. 
Figure 5. Distribution of ILDE edits among the 19 design artefacts that were edited by more than one teacher. The designs are identified by the group that created it and the tool used for its creation.

Interestingly, there were significant differences in the answers from the participating teachers when asked about their perception about the effectiveness of their group work (see [QuestPost $]^{\mathrm{ALL}}$ ). Indeed, groups 4 and 7 , the ones giving the lowest ratings to their collaboration effectiveness, also explicitly stated collaboration as one of the aspects to improve in the course (see, e.g., [Quest-Post $]^{4-\mathrm{A}}$, [Quest-Post $]^{7-\mathrm{A}}$ ). These inter-group communication problems can also be appreciated when looking at how the LD artefacts were edited in the ILDE by the individual group members (see Figure 5). For instance, in the case of group 4 $\left(\right.$ see $[\operatorname{Logs}]^{4-\mathrm{A}}$ and $[\operatorname{Logs}]^{4-\mathrm{B}}$ ), one of the group members did not actively edit one of the generated designs, there were several long time gaps between some of the editions, and most of the editing effort was carried out right before the delivery date of the corresponding design task. On the contrary, in the case of group 1, which valued very positively the collaboration within the group, the editing actions were much more balanced, and the reaction times after editions of other group members were also much shorter (see $\left.[\operatorname{Logs}]^{1-\mathrm{A}}\right)$.

Table 3. Selected excerpts of evidence for Topic 1 (Reaching consensus).

\section{Topic T2: Does the ILDE online support help educators complete a full-lifecycle co- design with ICT?}

Regarding the role of the ILDE in supporting the participants in their ICT-enhanced codesigns, the overall reaction seems rather positive: "it is an awesome tool that will be increasingly accepted in teaching practice. I do not know if in my University we have the possibility to connect it from Moodle. This way, I would not mind to make a request, asking my University to use it" [GeneralForum] ; "It has been a good experience in which I could learn a lot about the ILDE platform" [GeneralForum]"; "I have learnt new concepts as well as how to manage new ICT tools that I think could be very useful in the future" $[\text { GeneralForum }]^{7}$. Although several participants acknowledge (Table 4 contains the selected excerpts of evidence used in this section) that the ILDE is complex and not so easy to use at the beginning (see, e.g., [GeneralForum $]^{1-\mathrm{A}}$, [GeneralForum $]^{2-\mathrm{A}}$, [Quest-Post $]^{8-\mathrm{A}}$ ), they also value positively its support to collaborate, reach consensus, and share ideas about their learning designs (see, e.g., [GeneralForum $]^{1-\mathrm{B}}$, $[\text { GeneralForum }]^{2-\mathrm{B}}$ ). In fact, some groups have expressed their interest in using the ILDE platform for future teaching practice (see, e.g., $[\text { GeneralForum }]^{9-\mathrm{A}}$, [GeneralForum $]^{12-\mathrm{A}}$ ), even incorporating more complex learning designs (see, e.g., [GeneralForum $]^{3-A}$ ).

Interestingly, to the question "Which activity did you like the most?" [Quest-Post], 7 out of 18 participants answered "the deployment of the activities in Moodle [part of the 
implementations phase of the ILDE]", emphasizing the "possibility to see all the cycle completed as well as to better understand the whole process" [Quest-Post] ${ }^{3}$ and the fact that "I've seen our work in Moodle" [Quest-Post]". The deployment of the learning designs, i.e., the automatic setting up of the Moodle course according to the decisions made during the design process, is not a collaborative task. Thus, and although some team members helped each other during the deployment of the designs (see, e.g., [Posts] ${ }^{2-A}$ ), usually the actual deployment was carried out individually. As a consequence, some participants felt disappointed since they did not have the opportunity to contribute to that specific task (see, e.g., $\left.[\text { GeneralForum }]^{5-\mathrm{A}},[\text { Posts }]^{5-\mathrm{A}}\right)$.

However, during the course the participating teachers pointed out a variety of emerging difficulties of different nature in relation to the ILDE. 8 (out of 9) design groups explicitly complained about the lack of documentation and/or examples for better understanding the tasks they had to carry out (see, e.g., [Quest-Post $]^{3-\mathrm{A}}$, $[\text { Quest-Post }]^{4-\mathrm{A}}$, $[\text { Quest-Post }]^{5-\mathrm{A}}$, [QuestPost $\left.]^{10-\mathrm{A}}\right)$. Among the most frequently pointed out challenging issues, the participants mentioned the understanding of the terminology (see, e.g., [Quest-Post $]^{8-\mathrm{B}}$, $[\text { GeneralForum }]^{11}$ ) as well as the understanding of the exact role of the WebCollage authoring tool within the LD lifecycle (see, e.g., $\left.[\text { Posts }]^{1-\mathrm{A}},{ }_{\text {Posts }}\right]^{3-\mathrm{A}}$ ). In several cases, the ILDE is perceived as a complex platform to use, a complexity derived from the integration of different LD tools (see, e.g., [Posts] ${ }^{4-\mathrm{A}}$, [Quest-Post ${ }^{8-\mathrm{C}}$ ),

However, in spite of these difficulties, 6 out of the 9 participating groups were able to complete the whole LD cycle, including the implementation of their designs into a Moodle course. Groups 8, 10, and 12 were not able to complete the implementation phase, which is consistent with their level of activity during the course (see number of editions in Figure 5, previous section). On the contrary, groups 1 and 2, which showed a high level of activity in terms of number of editions of their designs (see again Figure 5), carried out a complete implementation of their designs [Designs]. The remaining groups $(3,4,5,6)$ were able to implement correctly only parts of their designs, in some cases with the help of the facilitator, who was satisfied with those partial implementations as a way of illustrating the complete design process [Designs].

During the unfolding of the course some sporadic technical glitches emerged, mostly related with Internet access problems and with compatibility issues among the ILDE and Internet browsers (see, e.g., [Posts $]^{1-\mathrm{B}},[\text { Posts }]^{7-\mathrm{A}}$ ).

Table 4. Selected excerpts of evidence for Topic 2 (ILDE support).

\section{Discussion, conclusions, future work}

The analysis of the evidence gathered in this study sheds some light on the tackled research question: how to support teachers in interuniversity teams to collaborate fully online along the LD process of a discipline-based situation that integrates ICT? 
The interpretation of the findings suggest that the instructional models of this type of online TPD might avoid potential barriers for effective co-design by: distributing roles and tasks among group members; facilitating explicit communication channels not only for design purposes but also for group coordination (e.g., explicitly asking for feedback before a certain deadline, availability for contributing); and, providing feedback and assistance by the course facilitators, which might contribute to better levels of motivation and co-design interaction.

Additionally, the findings suggest that the ILDE provides an adequate support for codesigning online, being its full-lifecycle nature one of the most appreciated features. However, the use of ILDE-like platforms for TPD requires the instructional model to anticipate the learning curve of the co-design platform, especially when it implies, as in the case of the ILDE, the use of different design tools along the design lifecycle. The participants in the study provide some suggestions in this regard: providing tutorials and/or examples for better understanding the ILDE-supported tasks to carry out, as well as the phases of the codesign lifecycle; and, allocating longer time slots for fine-grained design tasks such as those related with the authoring phase.

These conclusions provide a roadmap for future improvements, applicable not only to TPD models based on online co-design, but also to full-lifecycle LD platforms, such as the ILDE, who made possible the challenging showcased TPD scenario. Other future research avenues include: exploring the online co-design TPD approach educational contexts different from Higher Education; exploring group dynamics for better coping with the learning curve of the online co-design platform (e.g., each group member becomes "expert" in specific design tools); and, exploring the effectiveness of this approach to TPD when embedded in formal institutional programmes for teacher training.

\section{References}

Conole, G. (2013). Designing for learning in an open world. Springer: New York.

Conole, G., \& Culver, J. (2009). Cloudworks: Social networking for learning design. Australasian Journal of Educational Technology, 25(5), 763-782. doi: 10.14742/ajet.1120

Dobozy, E., \& Campbell, C. (2016). The complementary nature of Learning Design and TPACK. In J. Dalziel (Ed.), Learning Design: Conceptualizing a Framework for Teaching and Learning Online (pp. 96-116). London: Routledge.

Gros, B., Escofet, A., \& Marimón-Martí, M. (2016). Los patrones de diseño como herramientas para guiar la práctica del profesorado. RELATEC, Revista Latinoamericana de Tecnología Educativa, 15(3). doi: 10.17398/1695-288X.15.3.11 
Guba, E. (1981). Criteria for assessing the trustworthiness of naturalistic inquiries. Journal of Theory, Research, and Development on Educational Communication and Technology, 29, 75-91.

Author (2014).

Author (2014).

Author (2011).

Kali, Y., Markauskaite, L., Goodyear, P., \& Ward, M.-H. (2011). Bridging Multiple Expertise in Collaborative Design for Technology-Enhanced Learning. In The Computer Supported Collaborative Learning (CSCL) Conference 2011, Volume 2 (pp. 831-835).

Laurillard, D. (2012). Teaching as a Design Science: Building Pedagogical Patterns for Learning and Technology. London: Routledge.

McKenney, S., Kali, Y., Markauskaite, L., \& Voogt, J. (2015). Teacher design knowledge for technology enhanced learning: an ecological framework for investigating assets and needs. Instructional Science, 43, 181-202. doi:10.1007/s11251-014-9337-2

Author (2016).

Miles, M. B., Huberman, A. M., \& Saldaña, J. (2013). Qualitative data analysis: A methods sourcebook. SAGE Publications.

Mishra, P., \& Koehler, J. (2006). Technological Pedagogical Content Knowledge: A new framework for teacher knowledge. Teachers College Record, 108(6), 1017-1054. doi: $10.1111 / \mathrm{j} .1467-9620.2006 .00684 . x$

Mor, Y., \& Mogilevsky, O. (2013). The Learning Design Studio: Collaborative Design Inquiry as Teachers' Professional Development. Research in Learning Technology, 21. doi:10.3402/rlt.v21i0.22054

Author (2016).

Prieto, L., Dimitriadis, Y., Craft, B., Derntl, M., Émin, V., Katsamani, M., Laurillard, D., Masterman, E., Retalis, S., \& Villasclaras, E. (2013). Learning design Rashomon II: exploring one lesson through multiple tools. Research In Learning Technology, 21. doi: $10.3402 /$ rlt.v21i0.20057 
Reilly, E., \& Literat, I. (2012). Designing with Teachers: Participatory Approaches to Professional Development in Education. USCAnnenberg Innovation Lab.

Ronen-Fuhrmann, T., \& Kali, Y. (2015). Concretization of design ideas in the context of educational technology design. In M., Maina, B., Craft Brock, \& Y., Mor (Eds.), The Art \& Science of Learning Design (pp. 31-47). SensePublishers.

Saldaña, J. (2015). The coding manual for qualitative researchers. SAGE Publications.

Shamir-Inbal, T., \& Kali, Y. (2009). Teachers as designers of online activities: The role of socio-constructivist pedagogies in sustaining implementation. Design Principles \& Practices: An International Journal, 3(1), 89-100.

Voogt, J., Laferrière, T., Breuleux, A., Itow, R. C., Hickey, D. T., \& McKenney, S. (2015). Collaborative design as a form of professional development. Instr Sci, 43, 259-282. doi: 10.1007/s11251-014-9340-7

Yin, R. K. (2009). Designing Case Studies. Identifying Your Case(s) and Establishing the Logic of Your Case Study. In Case Study Research: Design and Methods (pp. 25-65). USA: SAGE Publications. 


\begin{tabular}{|l|l|l|}
\hline Group Id & Teaching field & $\begin{array}{l}\text { Number of } \\
\text { participants }\end{array}$ \\
\hline G1 & Modern philology & 3 \\
\hline G2 & Management and business & 2 \\
\hline G3 & Economics & 3 \\
\hline G4 & Engineering & 3 \\
\hline G5 & Didactics of language and literature & 2 \\
\hline G7 & Didactics of experimental sciences & 2 \\
\hline G8 & Social and educational sciences & 3 \\
\hline G10 & Classical philology & 2 \\
\hline G12 & Pharmacology & 2 \\
\hline & Total & $\mathbf{2 2}$ \\
\hline
\end{tabular}

Table 1. Configuration of the groups in the course. 


\begin{tabular}{|l|l|l|}
\hline \multicolumn{1}{|c|}{$\begin{array}{c}\text { Data Source } \\
\text { Type }\end{array}$} & \multicolumn{1}{|c|}{ Label } & \multicolumn{1}{c|}{ Definition } \\
\hline Team Forums & [Posts] & $\begin{array}{l}\text { Messages posted (asynchronously) by members of the } \\
\text { groups in order to share opinions and/or give feedback } \\
\text { to others (Forums provided by Moodle). }\end{array}$ \\
\hline Activity Logs & [Logs] & $\begin{array}{l}\text { ILDE logs indicating who edited the designs (and } \\
\text { when).. }\end{array}$ \\
\hline Questionnaires & [Quest-Pre] & $\begin{array}{l}\text { Open-ended and closed items for collecting data about } \\
\text { the experience, the background, and expectations of } \\
\text { the participants before the course started. }\end{array}$ \\
\hline Questionnaires & [Quest-Post $]$ & $\begin{array}{l}\text { Open-ended and closed items to collect the opinion of } \\
\text { the participants about co-design tasks and ILDE } \\
\text { support, after the course finished. }\end{array}$ \\
\hline Designs & [Designs $]$ & $\begin{array}{l}\text { Collection of teachers' learning design artifacts } \\
\text { created in the ILDE. }\end{array}$ \\
\hline $\begin{array}{l}\text { General } \\
\text { Forums }\end{array}$ & [GeneralForums $]$ & $\begin{array}{l}\text { Messages posted (asynchronously) by the participants } \\
\text { reflecting about their experience as co-designers using } \\
\text { the ILDE (Forum provided by Moodle). }\end{array}$ \\
\hline
\end{tabular}

Table 2. Data sources and their definitions. 


\begin{tabular}{|c|c|c|}
\hline Data source & Group & Excerpt \\
\hline [Posts] & 1 & $\begin{array}{l}{ }^{\mathrm{A}}[\mathrm{PATeacher}]: \text { "In order to foster the use of ICTs, we can ask the students to } \\
\text { create a GoogleDocs document so that they can write down the improvement } \\
\text { actions in pairs; thus, everyone will benefit from the comments made by all } \\
\text { and, additionally, repetitions will be avoided. What do you think?" } \\
{ }^{\mathrm{B}}[\mathrm{JMTeacher]:} \mathrm{"Great!} \mathrm{I'll} \mathrm{take} \mathrm{a} \mathrm{look} \mathrm{at} \mathrm{it} \mathrm{tomorrow.} \mathrm{I'll} \mathrm{be} \mathrm{also} \mathrm{in} \mathrm{a} \\
\text { Conference on Thursday... and inform the others when they've made } \\
\text { changes." }\end{array}$ \\
\hline [Logs] & 1 & $\begin{array}{l}{ }^{A} \text { Editing moments (and editing teachers) of the first conceptualization design } \\
\text { of Group } 1 .\end{array}$ \\
\hline & & 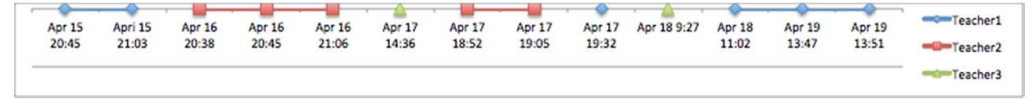 \\
\hline [Posts] & 2 & $\begin{array}{l}{ }^{\mathrm{A}}[\mathrm{CATeacher}]: \text { "I have seen that the activity can be divided in } 4 \text { sections. We } \\
\text { can divide the work according to these sections. I can develop ... and you can } \\
\text { edit .... Finally..." } \\
\\
{ }^{\mathrm{B}} \text { [CATeacher]: "I attach a Word document that contains ... I tried to include } \\
\text { it in ILDE but it was impossible. I can not edit." [GBTeacher]: "You cannot } \\
\text { probably edit the document because I was editing at the same time." } \\
\text { [CATeacher]: "Perfect!. I can edit." } \\
\text { [CATeacher]: "In resources, the coordinator pointed out that Moodle and } \\
\text { google can be deleted, because ... Tell me what you think." }\end{array}$ \\
\hline [Quest-Post] & 2 & $\begin{array}{l}\text { To the question: Did ILDE facilitate the codesign of a learning situation with } \\
\text { other teachers?. Answer: "I understand the design as a discipline that } \\
\text { requires experience. When you work in a collaborative team, you can } \\
\text { achieve better designs." }\end{array}$ \\
\hline [GeneralForum] & 2 & $\begin{array}{l}\text { A"I want to congratulate the coordinator for the huge work providing } \\
\text { feedback and help due to the lack of time and the number of groups." } \\
\text { B“'I'd suggest solving, however, the synchronisation problems, since in a } \\
\text { remote codesign each member has its own schedule and sometimes it is } \\
\text { difficult to follow the same working pace." }\end{array}$ \\
\hline [Posts] & 3 & $\begin{array}{l}{ }^{\mathrm{A}}[\mathrm{MAGTeacher}]: \text { "Hi, I added comments in ILDE on the section } \\
<<\text { information and comments }>>\text {. I prefer to introduce my comments this } \\
\text { way instead of putting the comments directly in the document." } \\
{ }^{\mathrm{B}} \text { [ASGTeacher]: "I send activity 2.1. I have opened a new thread for issues } \\
\text { about activity 2.2. I created a design in WebCollage and I edited the } \\
\text { objectives. We want to focus on the design flow but I am not sure how it } \\
\text { works. How can we share the work?". [CFTeacher]: "Hi ASG Thank you for } \\
\text { making the work more dynamic." }\end{array}$ \\
\hline [Quest-Post] & 3 & $\begin{array}{l}\text { ATo the question: "Please, indicate what might be improved [in the course]". } \\
\text { Answer: "Too short a time to appropriate things. It should last longer". }\end{array}$ \\
\hline
\end{tabular}


ATTeacher]: "We can make a brainstorming. I put several pictures in Google Drawings in the resources section. What will be the format?. We can use GoogleDocs."

${ }^{\mathrm{C}}$ [TCTeacher]: "I realized that we have an option in ILDE to put comments in the same design. I think that this is interesting, because it is easier to write there than on the forum."

A To the question: "Please, indicate what might be improved [in the course]". Answer: "I think it is a pity that communication problems and/or differences in personal goals within a group might imply the "failure" of the activity, without knowing (or being able) to avoid it."

${ }^{\mathrm{A}}$ Editing moments (and editing teachers) of the first conceptualization design of Group 4.

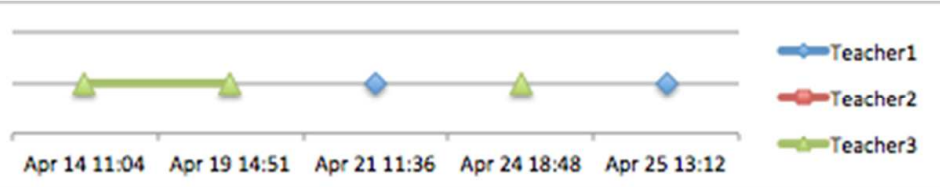

${ }^{\mathrm{B}}$ Editing moments (and editing teachers) of an improved version of the conceptualization design of Group 4.

${ }^{\mathrm{A}}$ [GTeacher]: "You can take a look at scoop.it as an example as well as a manual about how to use it http://www.scoop.it/t/language-learning-8"

B، This afternoon I'll take a look at the second activity; tomorrow I'm leaving for a conference and I don't know whether I'll be able to participate before next Monday, so if I don't post in the forum it is not because I've given up".

${ }^{\mathrm{A}}$ [FMTeacher]: "With respect to the pdfs, I do not know where they can be uploaded. Do you know it?" [MG Teacher]: "As far as I understood I think that we have to put a link with the resources."

${ }^{\mathrm{B}}$ [BMTeacher]: "The coordinator is asking us to put more effort in the following aspects: find real problems, [...]. I have been working in the two first. Can you take a look?"

${ }^{\mathrm{C}}$ [FMTeacher]: "Hi, I have been working in the Task 2.2 during this week. Take a look and feel free to introduce changes." [MGTeacher]: "The proposal is great! Awesome!. I added minor changes-"

${ }^{\text {A }}$ To the question: "Explain shortly you opinion about the online format of the course about ILDE". Answer: "It has been very positive, although working in groups online is very difficult. There is part of the group that works harder than the other, and communication is not good."

${ }^{\mathrm{B}}$ To the question: "please, specify how the course might be improved". 


\begin{tabular}{|c|c|c|}
\hline & & $\begin{array}{l}\text { Answer: "distributing the tasks among members, identifying and assigning } \\
\text { roles in each group, granting longer time for completing the tasks of the } \\
\text { course." }\end{array}$ \\
\hline [Posts $]$ & 8 & $\begin{array}{l}\text { A[ALTeacher]: "I always try to introduce contents in my designs related to } \\
\text { gender issues, inclusion, equal opportunities, ..." } \\
\text { B [ALTeacher] (editing without waiting for others' opinions): "I have logged } \\
\text { into the ILDE and I cannot see any shared activity, so I assume that no one } \\
\text { has been able to start it yet...Please feel free to make changes in the design } \\
\text { proposal." [ALTeacher] (starting a new activity without waiting for others" } \\
\text { opinions): "If all of you agree with the proposal, I can upload ... You can } \\
\text { feel free to modify whatever you want." [LRTeacher] (realizing that } \\
\text { [ALTeacher] has already progressed alone...): "Go ahead with the } \\
\text { publication of activity..." } \\
\text { cal It was a race against time, and I think that it was unnecessary. I am happy } \\
\text { that finally you can see the tasks completed. Everybody has criticized the } \\
\text { lack of time to process all the new information." }\end{array}$ \\
\hline [Quest-Post] & 8 & $\begin{array}{l}\text { To the question: "Explain shortly you opinion about the online format of the } \\
\text { course about ILDE". Answer: "I am not used to a completely online course } \\
\text { that has made the task difficult for me" }\end{array}$ \\
\hline [ILDE-Post] & 9 & [MAATeacher]: "I made the changes suggested by the course coordinator." \\
\hline [Posts] & 10 & $\begin{array}{l}{ }^{A}[\mathrm{METeacher}]: \text { "We have to collaborate to create a design using a template } \\
\text { in ILDE. We can create a document so that students practice the use of } \\
\text { connectors in academic writing. What do you think? (...). I can select the } \\
\text { competences and if you want you can describe the activities. I am going to } \\
\text { look for a template." }\end{array}$ \\
\hline [GeneralForum] & 10 & $\begin{array}{l}\text { A"The availability of the coordinator was very good and I appreciate it a } \\
\text { lot." }\end{array}$ \\
\hline [Quest-Post] & ALL & $\begin{array}{l}\text { To the question: "Please, rate the following aspects of the course }(1=\text { very } \\
\text { low, } 5=\text { very high) [Effectiveness of group organization]: out of the } 8 \text { groups } \\
\text { that answered: } \\
5 \text { (Groups } 1,10) \\
4 \text { (Groups } 2,3) \\
3 \text { (Groups } 5,8) \\
2 \text { (Group } 7) \\
1 \text { (Group } 4)\end{array}$ \\
\hline
\end{tabular}

Table 3. Selected excerpts of evidence for Topic 1 (Reaching consensus). 


\begin{tabular}{|c|c|c|}
\hline Data source & Group & Excerpt \\
\hline [Posts] & 1 & $\begin{array}{l}\text { A (When talking about problems in group configuration with WebCollage) } \\
\text { "No matter how much I search, I cannot see the problem. [...]. I think the } \\
\text { problem was in WebCollage, but I cannot find it". } \\
\text { B" The page cannot be loaded. My internet access at home doesn't work } \\
\text { properly". }\end{array}$ \\
\hline [GeneralForum] & 1 & $\begin{array}{l}{ }^{\mathrm{A}}[\mathrm{JMTeacher}] \text { "The ILDE platform is not simple to use, but quite useful and } \\
\text { well presented. I liked this course a lot, because I have had the opportunity } \\
\text { to learn unknown concepts and use tools that helps us reach common } \\
\text { objectives, proposals, ideas". } \\
{ }^{\mathrm{B}}[\mathrm{PATeacher]} \mathrm{"My} \mathrm{experience} \mathrm{working} \mathrm{in} \mathrm{groups} \mathrm{have} \mathrm{been} \mathrm{awesome.} \mathrm{We} \\
\text { have collaborated, we helped each other and each one of the members have } \\
\text { contributed with ideas. Group collaboration allows to learn from others and } \\
\text { shows other ways of teaching and learning. I have learnt a lot from my } \\
\text { colleagues". }\end{array}$ \\
\hline [Posts] & 2 & $\begin{array}{l}{ }^{\mathrm{A}}[\mathrm{CATeacher]:} \mathrm{"The} \mathrm{course} \mathrm{coordinator} \mathrm{asked} \mathrm{us} \mathrm{to} \mathrm{delete} \mathrm{the} \mathrm{resources} \\
\text { Moodle and Google, [...]. I would prefer to leave it like this, because we } \\
\text { have a better organization of what is supposed to be used. Anyway if you } \\
\text { want we can delete it. If you agree, we can deploy the design". [CATeacher]: } \\
\text { "It is awesome, it is rather complete!". }\end{array}$ \\
\hline [GeneralForum] & 2 & $\begin{array}{l}{ }^{\mathrm{A}}[\mathrm{GBTeacher}] \text { "Without doubt it have been a good experience to known } \\
\text { different possibilities to learning design. Being honest, the platform isn't } \\
\text { agile enough but once you have learned how to use it, is faster.". } \\
{ }^{\mathrm{B}}[\mathrm{GBTeacher]} \mathrm{"According} \mathrm{the} \mathrm{co-design} \mathrm{I} \mathrm{think} \mathrm{that} \mathrm{ICT} \mathrm{are} \mathrm{an} \mathrm{opportunity} \\
\text { to collaborate among teachers as designers around the world". }\end{array}$ \\
\hline [Posts] & 3 & $\begin{array}{l}\text { A“....and with WebCollage I don't know either what can be done nor its goal, } \\
\text { beyond creating a schema of the steps to take..." (Teacher 2): "[...] I was } \\
\text { trying to understand WebCollage because I'm not able to understand its } \\
\text { goal. I imagine we don't understand it because we're making a very basic } \\
\text { design...". }\end{array}$ \\
\hline [Quest-Post] & 3 & $\begin{array}{l}\text { ATo the question: "Please, indicate what might be improved [in the course]". } \\
\text { Answer: "Examples of implementations in different contexts". }\end{array}$ \\
\hline [GeneralForum] & 3 & $\begin{array}{l}\text { A"In our team, we have not developed a complex learning design. I would } \\
\text { like to put into practice more complex learning designs to see the process } \\
\text { step by step. Thus, I will do some research using the ILDE". }\end{array}$ \\
\hline [Posts] & 4 & $\begin{array}{l}\left.{ }^{\mathrm{A}}[\mathrm{Teacher}] \mathrm{S}\right] \text { "I have been lost in the manage of the tool. I know what I want } \\
\text { but when I used the platform I feel desperate". }\end{array}$ \\
\hline [Quest-Post] & 4 & $\begin{array}{l}\text { A To the question: "Please, indicate what might be improved [in the course]". } \\
\text { Answer: "Actually, there was no training at all. Only autonomous learning } \\
\text { without good guiding tutorials". }\end{array}$ \\
\hline [Posts] & 5 & $\begin{array}{l}\text { [GTeacher]: "The way in which certain activities were designed implied that } \\
\text { only one member of the group could be in charge of carrying it out. For this } \\
\text { reason, some members have not been able to practice. I think this has been } \\
\text { negative". }\end{array}$ \\
\hline
\end{tabular}




\begin{tabular}{|c|c|c|}
\hline [Quest-Post] & 5 & $\begin{array}{l}\text { A To the question: "Please, indicate what might be improved [in the course]". } \\
\text { Answer: "I think that it lacks more theory for framing the activities and } \\
\text { understanding their rationale". }\end{array}$ \\
\hline [GeneralForum] & 5 & $\begin{array}{l}\text { A"Regarding the collaboration in groups, there are some tasks that only a } \\
\text { person can make at the same time. Thus, some members have not been able } \\
\text { to practice certain steps. Maybe this can be improved in the future". }\end{array}$ \\
\hline [Posts] & 7 & $\begin{array}{l}\text { A“"Let me tell you that at the beginning I couldn't input resources and goals } \\
\text { [in WebCollage] because the browser didn't work well. I was working with } \\
\text { Chrome, then I switched to Firefox, and now I can enter them". }\end{array}$ \\
\hline [Quest-Post] & 8 & $\begin{array}{l}{ }^{\mathrm{A}} \text { To the question: "Describe shortly the reason for your } \\
\text { agreement/disagreement with the following question: Did the ILDE facilitate } \\
\text { the codesign of a learning situation with other teachers?". Answer: "It was a } \\
\text { new tool and at the very beginning I did not have a clear idea". } \\
\\
{ }^{\mathrm{B}} \text { To the question "Please, indicate what might be improved [in the course]". } \\
\text { Answer: "Generally speaking, I'd change the initial readings, since they } \\
\text { used a terminology I'm not familiar with". } \\
{ }^{\mathrm{C}} \text { To the question: "Explain shortly you opinion about the online format of the } \\
\text { course about the ILDE". Answer: "Maybe too many platforms. If they all } \\
\text { could be integrated in a single one, everything would be simpler". }\end{array}$ \\
\hline [Quest-Post] & 10 & $\begin{array}{l}{ }^{\mathrm{A}} \text { To the question: "Please, indicate what might be improved [in the course]". } \\
\text { Answer: "For the practical assignments I needed some more information or } \\
\text { clearer information". }\end{array}$ \\
\hline [GeneralForum] & 9 & $\begin{array}{l}\text { A"I have to recognize that it was a pleasure see what we can use this kind of } \\
\text { tools in social sciences courses. We have to overcome limitations between } \\
\text { pure sciences and social sciences and the use of ICT. I will use this kind of } \\
\text { activities in the next course". }\end{array}$ \\
\hline [GeneralForum] & 11 & $\begin{array}{l}\text { "It's true that the use of language (e.g., technical terms) and the way to work } \\
\text { within the course are complex. I'm not sure I'm understanding well enough } \\
\text { how ILDE works". }\end{array}$ \\
\hline [GeneralForum] & 12 & $\begin{array}{l}{ }^{\mathrm{A}}[\mathrm{TMTeacher}] \text { "I think that ILDE is a good tool, and I will use it in the } \\
\text { future. I think that it can be a complement to Moodle". }\end{array}$ \\
\hline
\end{tabular}

Table 4. Selected excerpts of evidence for Topic 2 (ILDE support). 


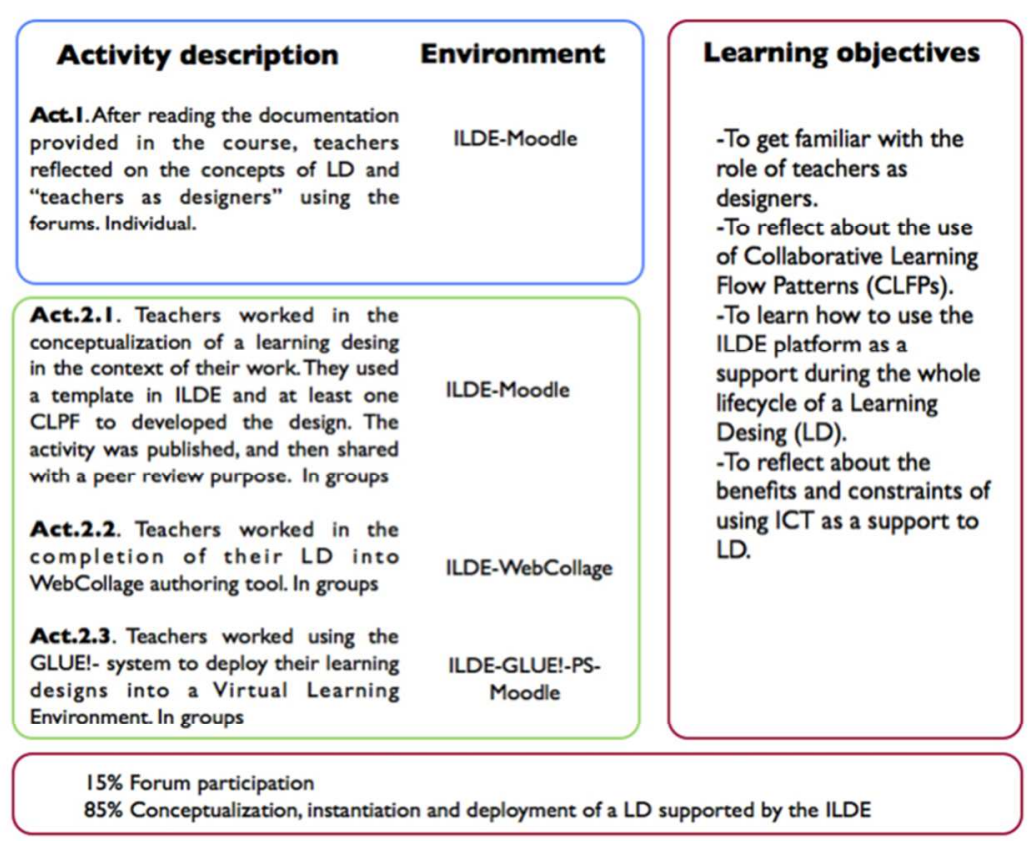

Figure 1. Description of the TPD course explored in the study. WebCollage and Glue!-PS are authoring and implementation tools, respectively, integrated within the ILDE. 
$(R Q):$ How to support teachers in interuniversity teams to collaborate fully online along the learning design process of a discipline-based situation that integrates ICTs?

Figure 2. Data condensation diagram, inspired from Miles, Huberman and Saldaña (2013), showing the Research Question (RQ), Issue (I), topics (T), and informative questions (IQ).

(Issue I1): How does the ILDE online co-design support help educators reach consensus and follow a full-lifecycle design process?

IQ1.1. How do design teams reach consensus about their designs?

IQ1.2 What are the main difficulties for achieving consensus?

ficulties for completing the co-design processes?

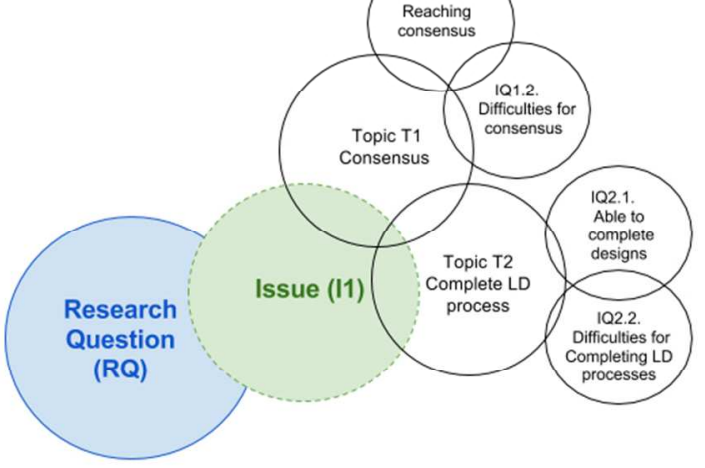




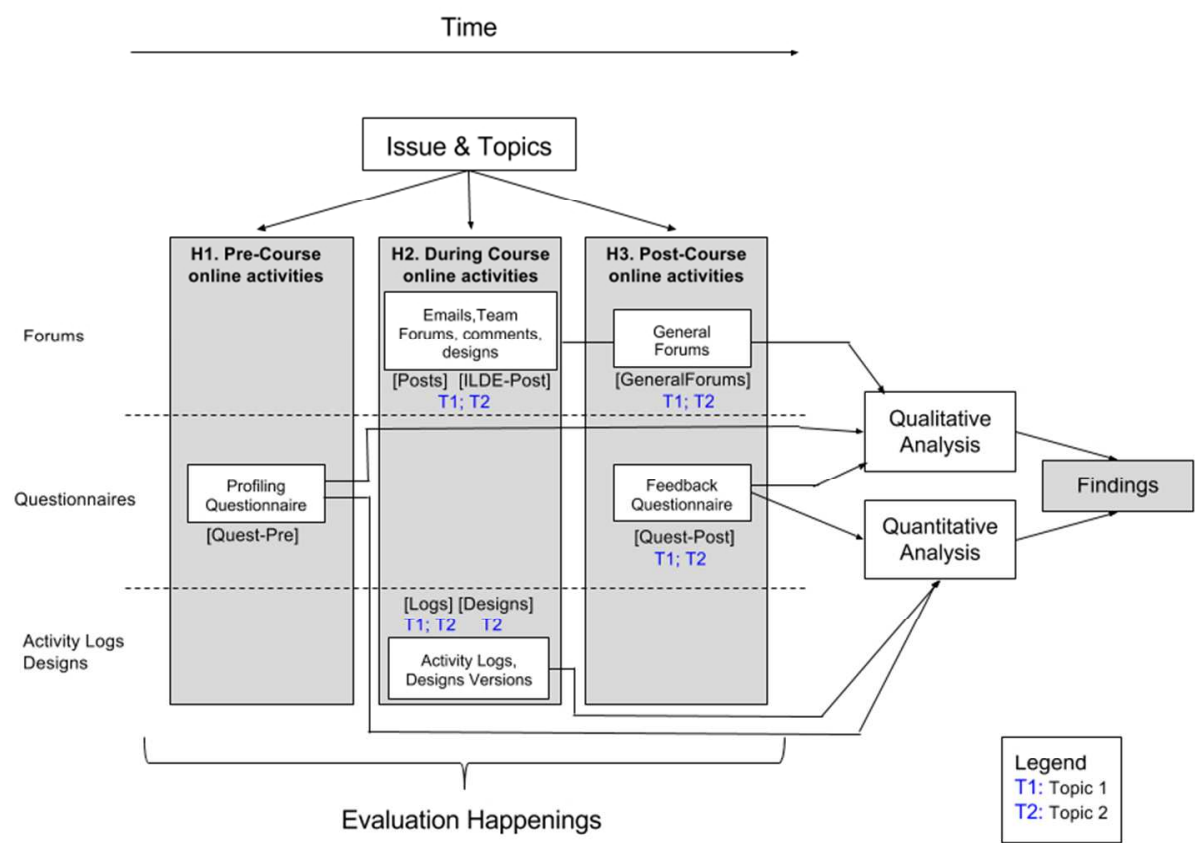

Figure 3. Data gathering moments and analysis techniques during the study. See Table 2 for an explanation of the labels. 


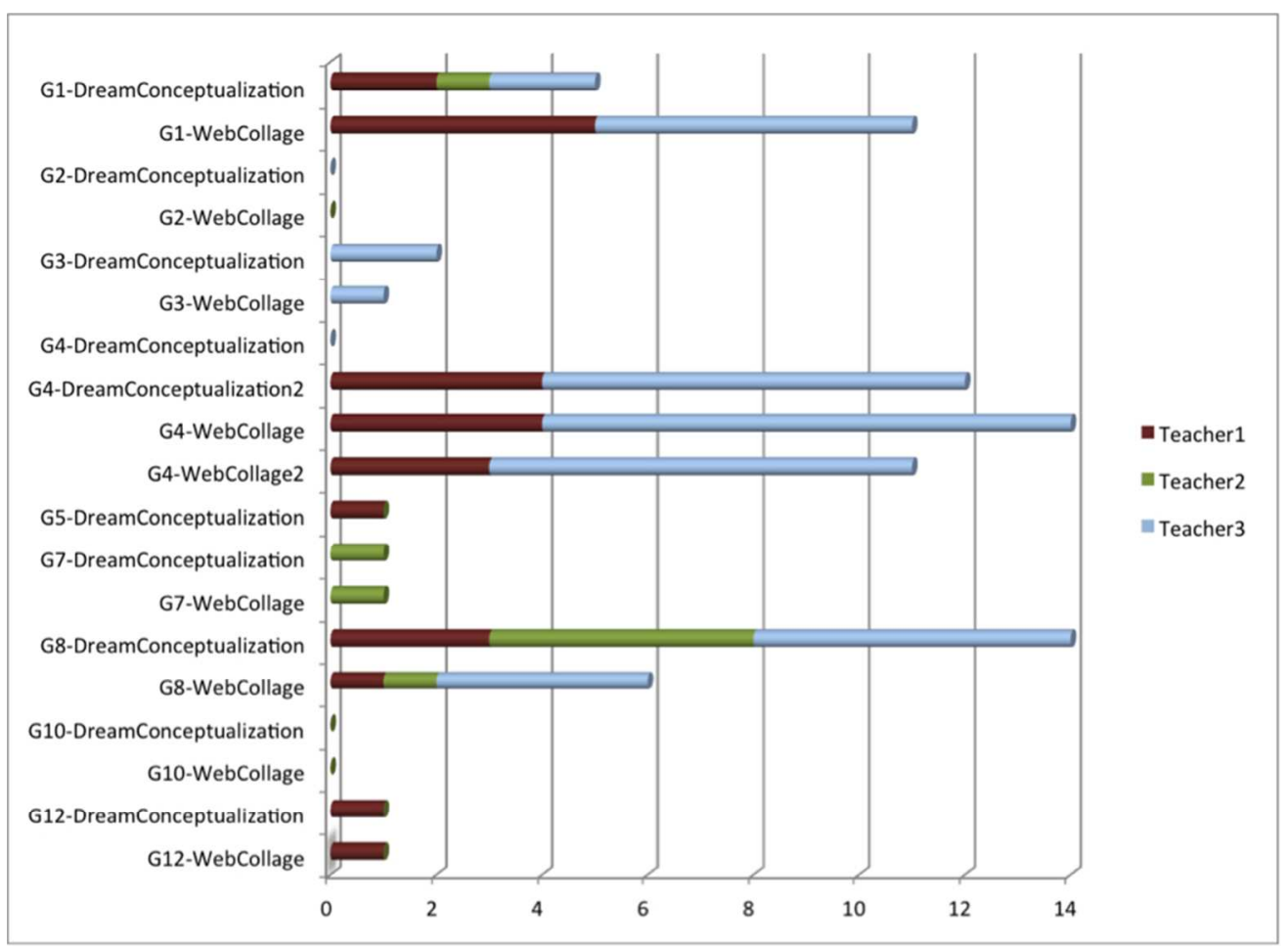

Figure 4. Distribution of ILDE comments among the 19 design artefacts that were edited by more than one teacher. The designs are identified by the group that created it, as well as by the tool used for its creation.

$159 \times 116 \mathrm{~mm}(150 \times 150 \mathrm{DPI})$ 
Figure 5. Distribution of ILDE edits among the 19 design artefacts that were edited by more than one teacher. The designs are identified by the group that created it and the tool used for its creation.

$159 \times 111 \mathrm{~mm}(150 \times 150 \mathrm{DPI})$ 


\section{Complete version of Table 3. Selected excerpts of evidence for Topic 1 (Reaching consensus).}

\begin{tabular}{|c|c|c|}
\hline Data source & Group & Excerpt \\
\hline [Posts] & 1 & $\begin{array}{l}\mathrm{A} \text { [PA Teacher]: "In order to foster the use of ICTs, we can ask the students to } \\
\text { create a GoogleDocs document so that they can write down the improvement } \\
\text { actions in pairs; thus, everyone will benefit from the comments made by all } \\
\text { and, additionally, repetitions will be avoided. What do you think?" } \\
\text { B[JM Teacher]: "I introduced modifications in WebCollage in the teacher } \\
\text { section. What do you think?" } \\
\text { C[JM Teacher]: "Great! I'll take a look at it tomorrow. I'll be also in a } \\
\text { Conference on Thursday and Friday" and inform the others when they've } \\
\text { made changes." } \\
\text { D[RS Teacher] "I started the activity 2.3, although I do not have much time to } \\
\text { devote to it, I will take a look next week when I come back from the } \\
\text { congress." }\end{array}$ \\
\hline$[\operatorname{Logs}]$ & 1 & $\begin{array}{l}\text { A Editing moments (and editing teachers) of the first conceptualization design } \\
\text { of Group } 1 .\end{array}$ \\
\hline & & 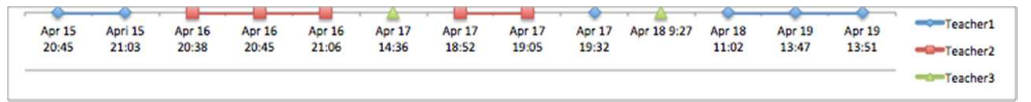 \\
\hline [Posts] & 2 & 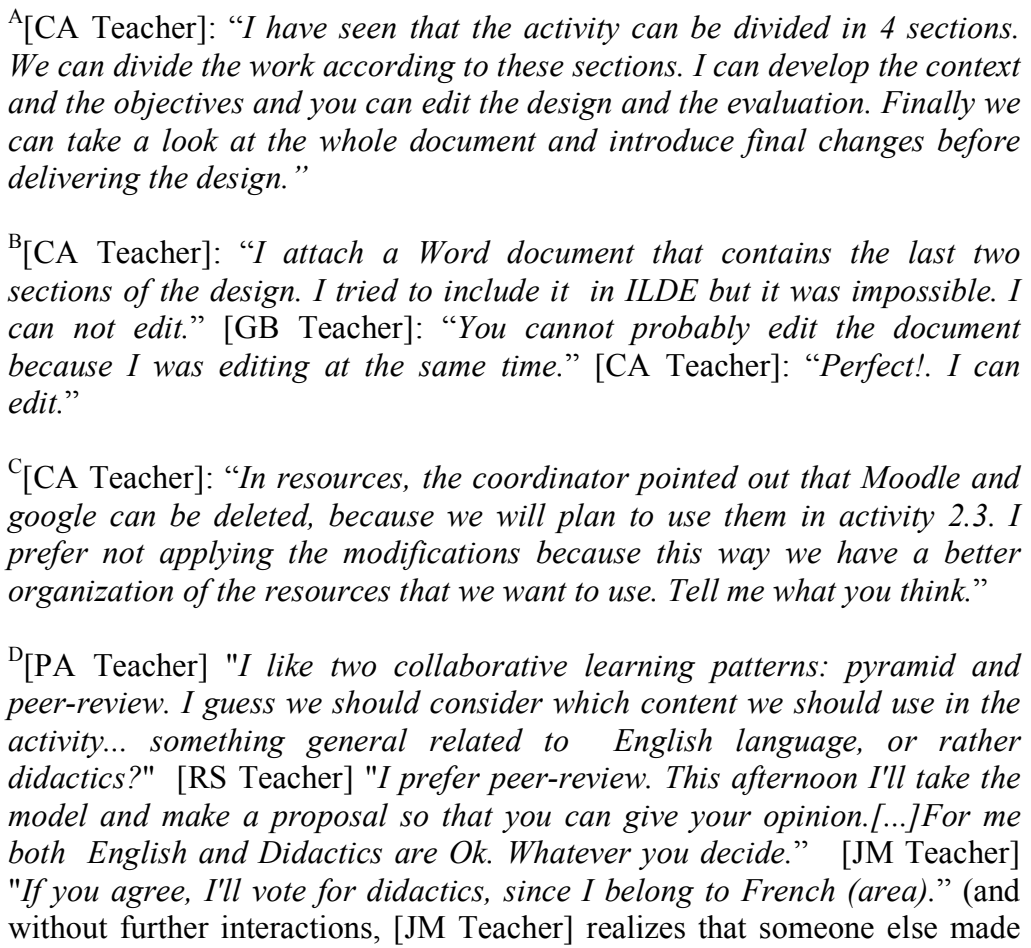 \\
\hline
\end{tabular}


changes to the co-design...) [JM Teacher] "I've checked that activity 2 is quite complete."

To the question: Describe shortly the reason for your agreement/disagreement with the following question: Did ILDE facilitate the codesign of a learning situation with other teachers?. Answer: "I understand the design as a discipline that requires experience. When you work in a collaborative team, you can achieve better designs."

\begin{tabular}{|c|c|c|}
\hline [GeneralForum] & 2 & $\begin{array}{l}\text { A"I want to congratulate the coordinator for the huge work providing } \\
\text { feedback and help due to the lack of time and the number of groups." } \\
\text { B"I'd suggest solving, however, the synchronisation problems, since in a } \\
\text { remote codesign each member has its own schedule and sometimes it is } \\
\text { difficult to follow the same working pace." }\end{array}$ \\
\hline [Posts] & 3 & $\begin{array}{l}{ }^{\mathrm{A}}[\mathrm{CF} \text { Teacher]: "I begin to feel lost, due to the use of the tool (WebCollage) } \\
\text { and because I do not know what we want to do in the next step. We made a } \\
\text { design flow but I do not know what the objective of this activity is and what } \\
\text { we can do with WebCollage. What do we have to do? A graphic with all the } \\
\text { steps to be followed? A didactic unit?. In Moodle we can make all these } \\
\text { things. What do you think ASG Teacher?." } \\
{ }^{\mathrm{B}}[\mathrm{MAG} \text { Teacher]: "Hi, I added comments in ILDE on the section } \\
\text { <<information and comments >>. I prefer to introduce my comments this } \\
\text { way instead of putting the comments directly in the document." } \\
{ }^{\mathrm{C}} \text { [ASG Teacher]: "Tomorrow is the last day to deliver the task. I will be very } \\
\text { busy tomorrow but I can devote time to complete the activity at midday and } \\
\text { at the end of the day." [ASG Teacher]: "I am very busy but tonight or } \\
\text { tomorrow morning I can devote time to activity 2.3." [CF Teacher] "No } \\
\text { worries. Until Wednesday I have a crazy schedule, so we will see how can } \\
\text { we organize it without problems." } \\
\text { D } \\
\text { [ASG Teacher]: "I send activity 2.1. I have opened a new thread for issues } \\
\text { about activity 2.2. I created a design in WebCollage and I edited the } \\
\text { objectives. We want to focus on the design flow but I am not sure how it } \\
\text { works. How can we share the work?". [CF Teacher]: "Hi ASG Thank you for } \\
\text { making the work more dynamic." }\end{array}$ \\
\hline [Quest-Post] & 3 & $\begin{array}{l}\text { A To the question: "Please, indicate what might be improved [in the course]". } \\
\text { Answer: "Too short a time to appropriate things. It should last longer". }\end{array}$ \\
\hline [Posts] & 4 & $\begin{array}{l}{ }^{\mathrm{A}}[\mathrm{T} \text { Teacher]: "We can make a brainstorming. I put several pictures in } \\
\text { Google Drawings in the resources section. I think that we should help } \\
\text { students with questions to focus on specific aspects: e.g. how many bicycles?, } \\
\text { What will be the format?. We can use GoogleDocs." } \\
{ }^{\mathrm{B}}[\mathrm{TC} \text { Teacher]: "Take a look at what I have found. It is a Master Degree } \\
\text { Thesis about the design and selection of materials for a bicycle parking } \\
\text { http://repositori.uji.es/xmlui/bitstream/handle/10234/107522/TFM_2013_ten } \\
\text { aD.pdf" } \\
{ }^{\mathrm{C}}[\mathrm{TC} \text { Teacher]: "I realized that we have an option in ILDE (view section in } \\
\text { the toolbar) to put comments in the same design. I think that this is } \\
\text { interesting, because it is easier to write there than on the forum. I put some } \\
\text { comments about our design." } \\
{ }^{\mathrm{D}}[\mathrm{T} \text { Teacher] "I have a trip tomorrow, I do not have Internet until Sunday. } \\
\text { Please can you go ahead with the LDs?. When I come back I will take a look }\end{array}$ \\
\hline
\end{tabular}




\begin{tabular}{|c|c|c|}
\hline & & $\begin{array}{l}\text { at the advances made in activity } 2.2 \text { and I will make contributions." } \\
\text { E“I must confess that I feel very frustrated. I don't like leaving tasks } \\
\text { unfinished... but we're a team and, well, what we do is a joint decision. I } \\
\text { understand that you have other responsibilities and lack of time and you can } \\
\text { devote more time: nobody told us that collaboration and coordination would } \\
\text { be "compulsory." }\end{array}$ \\
\hline [Quest-Post] & 4 & $\begin{array}{l}\text { A To the question: "Please, indicate what might be improved [in the course]". } \\
\text { Answer: "I think it is a pity that communication problems and/or differences } \\
\text { in personal goals within a group might imply the "failure" of the activity, } \\
\text { without knowing (or being able) to avoid it." }\end{array}$ \\
\hline \multirow[t]{4}{*}{ [Logs] } & \multirow[t]{4}{*}{4} & $\begin{array}{l}\text { A Editing moments (and editing teachers) of the first conceptualization design } \\
\text { of Group } 4 .\end{array}$ \\
\hline & & \begin{tabular}{|l|l|l|l|l} 
Apr 14 11:04 & Apr 19 14:51 Apr 21 11:36 Apr 24 18:48 & Apr 25 13:12 & -Teacher1 \\
-Teacher3
\end{tabular} \\
\hline & & $\begin{array}{l}{ }^{\mathrm{B}} \text { Editing moments (and editing teachers) of an improved version of the } \\
\text { conceptualization design of Group } 4 .\end{array}$ \\
\hline & & 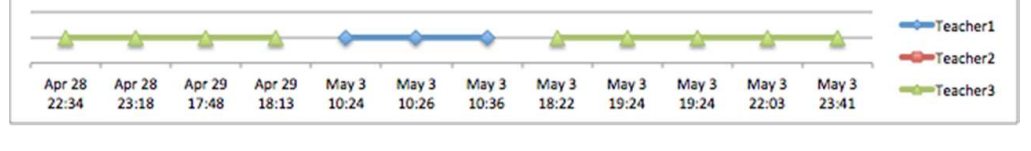 \\
\hline [Posts] & 5 & $\begin{array}{l}\text { A [G Teacher]: "You can take a look at scoop.it as an example as well as a } \\
\text { manual about how to use it } \\
\text { http://www.scoop.it/t/language-learning-8 } \\
\text { http://es.slideshare.net/flosflorum2/tutorial-scoopit-en-espaol-paso-a-paso)" } \\
\text { Bu"This afternoon I'll take a look at the second activity; tomorrow I'm leaving } \\
\text { for a conference and I don't know whether I'll be able to participate before } \\
\text { next Monday, so if I don't post in the forum it is not because I've given up". }\end{array}$ \\
\hline [Posts] & 7 & $\begin{array}{l}\text { A[FMTeacher]: "With respect to the pdfs, I do not know where they can be } \\
\text { uploaded. Do you know it?" [MGTeacher]: "As far as I understood I think } \\
\text { that we have to put a link with the resources. We can upload the documents } \\
\text { to dropbox and get the shared link." } \\
\\
\text { B[BM Teacher]: "The coordinator is asking us to put more effort in the } \\
\text { following aspects: find real problems, provide a guide to the students to help } \\
\text { them in problem solving, generate a pdf with instructions, create a } \\
\text { questionnaire. I have been working in the two first. Can you take a look?" } \\
\text { C[FMTeacher]: "Hi, I have been working in the Task } 2.2 \text { during this week. } \\
\text { Take a look and feel free to introduce changes." [MGTeacher]: "The } \\
\text { proposal is great! Awesome!. I added minor changes-" }\end{array}$ \\
\hline [Quest-Post] & 7 & $\begin{array}{l}\mathrm{A} \text { To the question: "Explain shortly you opinion about the online format of the } \\
\text { course about ILDE". Answer: "It has been very positive, although working in } \\
\text { groups online is very difficult. There is part of the group that works harder }\end{array}$ \\
\hline
\end{tabular}




\section{Complete version of Table 4. Selected excerpts of evidence for Topic 2 (ILDE support).}

\begin{tabular}{|c|c|c|}
\hline Data source & Group & Excerpt \\
\hline [Posts] & 1 & $\begin{array}{l}\text { A(When talking about problems in group configuration with WebCollage) } \\
\text { "No matter how much I search, I cannot see the problem. We might deliver } \\
\text { it, no?. I think the problem was in WebCollage, but I cannot find it". } \\
\text { B"The page cannot be loaded. My internet access at home does not work } \\
\text { properly". }\end{array}$ \\
\hline [Quest-Post] & 1 & $\begin{array}{l}\text { A To the question: "Please, indicate what might be improved [in the course]". } \\
\text { Answer: "Maybe some information about the workflow diagrams [in } \\
\text { WebCollage], but everything has been unimprovable". } \\
\text { "To the question: "Please, indicate what might be improved [in the course]". } \\
\text { Answer: "An initial course about terminology, with doubts and answers". }\end{array}$ \\
\hline [GeneralForum] & 1 & $\begin{array}{l}{ }^{\mathrm{A}}[\mathrm{JMTeacher}] \text { "The ILDE platform is not simple to use, but quite useful and } \\
\text { well presented. I liked this course a lot, because I have had the opportunity } \\
\text { to learn unknown concepts and use tools that helps us reach common } \\
\text { objectives, proposals, ideas". } \\
\text { B }{ }^{\mathrm{B}} \text { [PATeacher] "My experience working in groups have been awesome. We } \\
\text { have collaborated, we helped each other and each one of the members have } \\
\text { contributed with their ideas. Group collaboration allows to learn from } \\
\text { others and shows other ways of teaching and learning. I have learnt a lot } \\
\text { from my colleagues". } \\
\text { "I think it was very useful to learn how to use ILDE. I'm sure that I will use } \\
\text { it the next academic year". }\end{array}$ \\
\hline [Posts] & 2 & $\begin{array}{l}{ }^{\mathrm{A}}[\mathrm{CATeacher]} \text { : "The course coordinator asked us to delete the resources } \\
\text { Moodle and Google, because we included them in activity 2.3. I would prefer } \\
\text { to leave it like this, because we have a better organization of what is } \\
\text { supposed to be used. Anyway if you want we can delete it. If you agree, we } \\
\text { can deploy the design". [CATeacher]: "It is awesome, it is rather complete!". } \\
\text { B"In any case, if you still have problems, try with a different Internet } \\
\text { browser. Mine is not working very well either". }\end{array}$ \\
\hline [Quest-Post] & 2 & $\begin{array}{l}\text { A To the question: "Please, indicate what might be improved [in the course]". } \\
\text { Answer: "Since many of us are not experienced [in the topic of the course], it } \\
\text { would be helpful to include some examples". }\end{array}$ \\
\hline [GeneralForum] & 2 & $\begin{array}{l}{ }^{\mathrm{A}}[\mathrm{GBT} \text { eacher] "Without doubt it have been a good experience to known } \\
\text { different possibilities to learning design. To be honest, the platform is not } \\
\text { agile enough but once you have learned how to use it, is faster. Moreover, I } \\
\text { supposed that many people is working to improve these learning design } \\
\text { tools". } \\
{ }^{\mathrm{B}} \text { [GBTeacher] "According the co-design I think that ICT are an opportunity } \\
\text { to collaborate among teachers as designers around the world". }\end{array}$ \\
\hline [Posts] & 3 & $\begin{array}{l}\text { A“....and with WebCollage I don't know either what can be done nor its goal, } \\
\text { beyond creating a schema of the steps to take...” (Teacher 2): “...I was trying } \\
\text { to understand WebCollage because I'm not able to understand its goal. I }\end{array}$ \\
\hline
\end{tabular}




\begin{tabular}{|c|c|c|}
\hline & & $\begin{array}{l}\text { imagine we don't understand it because we're making a very basic } \\
\text { design...". } \\
\text { B[ASG Teacher]: "I have made changes to a section for the discussion in } \\
\text { supergroups. I also added documents in Word and presentations. I have tried } \\
\text { to see the implementation in Moodle but I have problems with the password. } \\
\text { What a mess with the passwords!. I am waiting for a new password to arrive } \\
\text { via e-mail. Meanwhile you can take a look and tell me what you think". } \\
\text { [MAG Teacher]: "Hello, thanks [ASG Teacher]. I have seen the } \\
\text { implementation in Moodle. The password and the user is "***". I think that } \\
\text { the task is now completed. I do not know if I would have been able to do it } \\
\text { alone". }\end{array}$ \\
\hline [Quest-Post] & 3 & $\begin{array}{l}\text { A To the question: "Please, indicate what might be improved [in the course]". } \\
\text { Answer: "See examples of implementations in different contexts". }\end{array}$ \\
\hline [GeneralForum] & 3 & $\begin{array}{l}\text { A“'In our team, we have not developed a complex learning design. I would } \\
\text { like to put into practice more complex learning designs to see the process } \\
\text { step by step. Thus, I will do some research using the [ILDE] platform". }\end{array}$ \\
\hline [Posts] & 4 & $\begin{array}{l}{ }^{\mathrm{A}}[\text { TeacherS]: "I have been lost in the manage of the tool. I know what I want } \\
\text { but when I used the platform I feel desperate". }\end{array}$ \\
\hline [Quest-Post] & 4 & $\begin{array}{l}\text { ATo the question: "Please, indicate what might be improved [in the course]". } \\
\text { Answer: "Actually, there was no training at all. Only autonomous learning } \\
\text { without good guiding tutorials". }\end{array}$ \\
\hline [Posts] & 5 & $\begin{array}{l}\text { [GTeacher]: "The way in which certain activities were designed implied that } \\
\text { only one member of the group could be in charge of carrying it out. For this } \\
\text { reason, some members have not been able to practice. I think this has been } \\
\text { negative. I am sorry". }\end{array}$ \\
\hline [Quest-Post] & 5 & $\begin{array}{l}\text { ATo the question: "Please, indicate what might be improved [in the course]". } \\
\text { Answer: "I think that it lacks more theory for framing the activities and } \\
\text { understanding their rationale". }\end{array}$ \\
\hline [GeneralForum] & 5 & $\begin{array}{l}\text { A“"The management of the tools it has been a bit complex to me, but I } \\
\text { understand that more practice is needed". } \\
\text { B“"Regarding the collaboration in groups, there are some tasks that only a } \\
\text { person can make at the same time. Thus, some members have not been able } \\
\text { to practice certain steps. Maybe this can be improved in the future". }\end{array}$ \\
\hline [Posts] & 7 & $\begin{array}{l}\text { A“'Let me tell you that at the beginning I couldn't input resources and goals } \\
\text { [in WebCollage] because the browser didn't work well. I was working with } \\
\text { Chrome, then I switched to Firefox, and now I can enter them". }\end{array}$ \\
\hline [Quest-Post] & 7 & $\begin{array}{l}\text { A To the question: "Explain shortly you opinion about the online format of the } \\
\text { course about the ILDE". Answer: "It is a bit complex to understand. I think it } \\
\text { should be made easier, maybe with videos?. In a tutorial fashion, for } \\
\text { instance". }\end{array}$ \\
\hline [Quest-Post] & 8 & $\begin{array}{l}\text { "To the question: "Describe shortly the reason for your } \\
\text { agreement/disagreement with the following question: Did the ILDE facilitate } \\
\text { the codesign of a learning situation with other teachers?". Answer: "It was a } \\
\text { new tool and at the very beginning I did not have a clear idea". } \\
\text { "To the question "Please, indicate what might be improved [in the course]". } \\
\text { Answer: "Generally speaking, I'd change the initial readings, since they } \\
\text { used a terminology I'm not familiar with". }\end{array}$ \\
\hline
\end{tabular}




\begin{tabular}{|c|c|c|}
\hline & & $\begin{array}{l}\text { To the question: "Explain shortly you opinion about the online format of the } \\
\text { course about the ILDE". Answer: "Maybe too many platforms. If they all } \\
\text { could be integrated in a single one, everything would be simpler". }\end{array}$ \\
\hline [Quest-Post] & 10 & $\begin{array}{l}\text { A To the question: "Please, indicate what might be improved [in the course]". } \\
\text { Answer: "For the practical assignments I needed some more information or } \\
\text { clearer information". }\end{array}$ \\
\hline [GeneralForum] & 9 & $\begin{array}{l}\text { A"I have to recognize that it was a pleasure see what we can use this kind of } \\
\text { tools in social sciences courses. We have to overcome limitations between } \\
\text { pure sciences and social sciences and the use of ICT. I will use this kind of } \\
\text { activities in the next course". }\end{array}$ \\
\hline [GeneralForum] & 10 & $\begin{array}{l}\text { [ER Teacher] "The course was interesting because I learn how to use a new } \\
\text { tool. I have had some problems in understanding its management, and I am } \\
\text { not sure if I finally understood it well". }\end{array}$ \\
\hline [Quest-Post] & 11 & $\begin{array}{l}\text { ATo the question: "Please, indicate what might be improved [in the course]". } \\
\text { Answer: "Some more practice to reinforce the knowledge". }\end{array}$ \\
\hline [GeneralForum] & 11 & $\begin{array}{l}\text { "It's true that the use of language (e.g., technical terms) and the way to work } \\
\text { within the course are complex. I'm not sure I'm understanding well enough } \\
\text { how ILDE works". }\end{array}$ \\
\hline [GeneralForum] & 12 & $\begin{array}{l}{ }^{\mathrm{A}}[\mathrm{TM} \text { Teacher] "I think that ILDE is a good tool, and I will use it in the } \\
\text { future. I think that it can be a complement to Moodle". } \\
{ }^{\mathrm{B}}[\mathrm{CM} \text { Teacher] "The course was easy to follow and the ILDE platform was a } \\
\text { nice discovery that I'm sure I will use in the future". }\end{array}$ \\
\hline
\end{tabular}

